Article

\title{
Inter-Seasonal Variations of Surface Temperature in the Urbanized Environment of Delhi Using Landsat Thermal Data
}

\author{
Ram Babu Singh ${ }^{1, *}$, Aakriti Grover ${ }^{2}$ and Jinyan Zhan $^{3}$ \\ 1 Department of Geography, Delhi School of Economics, University of Delhi, Delhi 110007, India \\ 2 Department of Geography, Swami Shraddhanand College, University of Delhi, Delhi 110036, India; \\ E-Mail: aakriti.grover@gmail.com \\ 3 State Key Laboratory of Water Environment Simulation, School of Environment, \\ Beijing Normal University, Beijing 100875, China; E-Mail: zhanjy@bnu.edu.cn \\ * Author to whom correspondence should be addressed; E-Mail: rbsgeo@hotmail.com; \\ Tel.: +91-9971950226.
}

Received: 29 January 2014; in revised form: 13 March 2014 / Accepted: 13 March 2014 / Published: 24 March 2014

\begin{abstract}
Complex land use/cover patterns in urban areas significantly influence their prevailing surface temperature conditions. As a result of differential cooling and heating of various land use/cover, large temperature ranges are associated with bare land, built-up land, etc. and low ranges are found in vegetation cover and water bodies. Extremely high and low temperature conditions in built-up land have direct and negative impacts on health conditions, and therefore are imperative to study. Thus, an attempt has been made in this research to analyze seasonal variations in surface temperature in city of Delhi. Landsat Thematic Mapper (TM) 5 satellite images for the four seasons, viz., 16 January (winter), 5 March (spring), 8 May (summer) and 29 September (autumn) 2011 have been used to interpret the distribution and changes in surface temperature. A total of 80 samples from all land use/cover categories were taken to generalize the patterns along with north-south and west-east profiles. The extracted surface temperature patterns reflect the spatial and temporal dynamics of temperature over different land use/cover. The north-south and west-east gradient of temperature demonstrates that the core of Delhi has a much lower temperature and weak urban heat island (UHI) phenomenon.
\end{abstract}

Keywords: Delhi; seasonal variation; micro climate; urban heat island (UHI); land use/cover 


\section{Introduction}

Urbanization has produced innumerable changes on the Earth and the associated surface temperatures. As urbanization takes place, rural and sub-urban areas are concretized and agricultural and vegetation cover is converted into urban areas, thereby altering the heat budget. Increased concretization and associated modifications of land use/cover in urban areas have altered the patterns of surface temperature creating distinct micro climates in cities and towns [1,2]. Additional heat is added to nearby areas by industries, vehicles, air conditioning and other activities peculiar to the urban lifestyle [3]. As a result, urban areas generally act as islands of elevated temperatures surrounded by the sea of relatively cooler suburbs [4]. The world is experiencing unprecedented urban growth. As per the United Nations (UN) Report on Cities and Climate Change: Global Report on Human Settlements [5], the number of cities in the world with populations greater than one million increased from 75 in 1950 to 447 in 2011 and it is projected that by 2020 there will be 527 such cities. According to UN [5], the total urban population of India was 364 million in 2010, which is projected to increase to 463 million by 2020 and 590 million by 2030 .

Land surface temperature (LST) is an indicator for measuring urban heat islands (UHIs) [6]. The surface temperature of an urban area is influenced by many factors like the length of day, season, wind, ocean currents, clouds, topography, location, rural surroundings, land use, building material and city geometry $[3,4]$. The surface temperature has indirect but considerably significant influence on air temperatures, especially the canopy layer that is closest to the surface [7]. The green areas covered by vegetation act as lungs of the city and help in regulating the temperature [8-10] thus observing low temperature. On the other hand, replacement of soil, water and vegetation by impervious asphalt, concrete, metal in urban areas has environmental implications including reduction in evapo-transpiration, rapid run-off and increase in surface temperatures $[8,10,11]$ leading to creation of UHIs. There are inter-seasonal variations in surface temperature of different land uses/cover $[7,12,13]$. The magnitude of surface UHIs varies with seasons, due to changes in the sun's intensity as well as ground cover and weather. As a result of such variation, surface UHIs are typically largest in the summer [14,15] though many studies have also shown intense UHI in winters [16].

The thermal environment is directly influenced by the physical surface conditions of the region [8]. The creation of UHI and changes in temperature has adverse effects on the biophysical components of the environment [4]. It also contributes to increased instances of heat stress and human mortality $[4,8,17]$. Thus, it is imperative to understand relationship between land use/cover and land-atmosphere energy exchange processes at local and regional scales [18]. As increasing land use/cover modifications take place because of urbanization, understanding the relationship between dynamics of LST and land use becomes crucial.

Approaches to urban thermal environment range from gathering data through fixed locations, mobile sampling of air through vehicles and much recently, the application of various remote sensing platforms [8,19,20]. Landsat Thematic Mapper/Enhanced Thematic Mapper Plus (TM/ETM+), Moderate Resolution Imaging Spectroradiometer (MODIS), Advanced Very High Resolution Radiometer (AVHRR), and Advanced Spaceborne Thermal Emission and Reflection (ASTER), Geostationary Operational Environmental Satellite (GOES) and Synthetic Aperture Radar Imager (SPOT) images have been extensively employed to analyze changes in surface temperature [21-23]. 
Research conducted using Landsat data for China is immense, e.g., Yue et al. [8] on relationship between LST, land use and NDVI of Shanghai. Weng et al. [24] estimated LST in relation to vegetation abundance. Amiri et al. [25] presented research on the city of Tabriz, Iran and Mallick et al. [26] presented relationship between changing land use/cover, surface temperature and emissivity for Delhi, India. MODIS and ASTER data is largely used to understand differences in day and night time UHI effect. Coll et al. [27] compared different sources of for LST retrieval thermal infrared data. Benali et al. [28] and Zakšek and Oštir [29] estimated surface temperature using MODIS data. Mallick et al. [30] relied on Landsat data while, Mohan et al. [31] used LISS III data for establishing relationship between urbanization and land use/cover of Delhi. On the other hand, Kant et al. [21] based the research using ASTER data and Roy et al. [32] by installing temperature recording instruments over Delhi.

Research on seasonal comparison of UHI were conducted by Li et al. [33] on seasonal change in UHI of Shanghai, Pandey et al. [34] examined summertime UHI over Delhi for day and night conditions, and Weng and Yang [35] on adverse thermal effects of urban development in the Chinese city of Guangzhou for the summer and winter seasons, while Streutker [36] examined it for Houston (TX, USA). Zhang et al. [37] and Yuan and Bauer [38] used Landsat data for seasonal analysis of UHI. However, application of use of Landsat dataset on seasonal changes in UHI of Delhi is scarce.

With this backdrop of gravity of problem and paucity of research on inter-seasonal variations in micro climate especially on Delhi, the present study is of paramount importance as it focuses on: (1) understanding the temporal relationship between the dynamics of LST for land use/cover types across the four seasons of Delhi; and (2) analyzing the inter - seasonal north-south and west-east surface temperature gradient.

\section{Study Area}

The capital city of India, Delhi located on the banks of the Yamuna River, has been selected for this study. It is a land-locked city, geographically situated at latitudinal extent of $28^{\circ} 23^{\prime} 17^{\prime \prime}-28^{\circ} 53^{\prime} 00^{\prime \prime} \mathrm{N}$ and longitudinal extent of $76^{\circ} 50^{\prime} 24^{\prime \prime}-77^{\circ} 20^{\prime} 37^{\prime \prime}$ E (Figure 1) covering an area of $1483 \mathrm{~km}^{2}$ with average altitude 213-305 m above mean sea level. The main features of physiography of Delhi are the Yamuna flood plain and the Aravalli ridge. The total length of the Yamuna River is about $48 \mathrm{~km}$ in Delhi, which passes through seven districts of Delhi [39]. The Delhi ridge is an extension of Aravalli Range and its spurs meet the Yamuna at two locations in Delhi, in the north and the east. This ridge acts as a barrier between the Thar Desert and the northern Indian plains. It also acts as a thermal moderator and cooling agent in the climate of Delhi. As per the records of the India State of Forest Report (FSI) [40], Delhi has an extreme climate with annual temperatures ranging from $3{ }^{\circ} \mathrm{C}$ in winters (January) to $45{ }^{\circ} \mathrm{C}$ in summers (June) and average rainfall from $400 \mathrm{~mm}$ to $600 \mathrm{~mm}$. Broadly, there are four seasons in Delhi, i.e., summers (May-July), spring/rainy (August-September), autumn (October-November) and winters (December-February). Summers are long and extremely hot accompanied with frequent dust storms. Humidity level is high during the monsoon season, while the air is dry during the rest of the year [21,40]. 
Figure 1. Location of study area on Landsat Thematic Mapper (TM) 5 satellite image in India. The red color represent vegetation surface, sky blue the urban and rural built-up area, pink-grey-cyan agriculture, dark blue-grayish blue-black the water and river, light sky blue the sands.

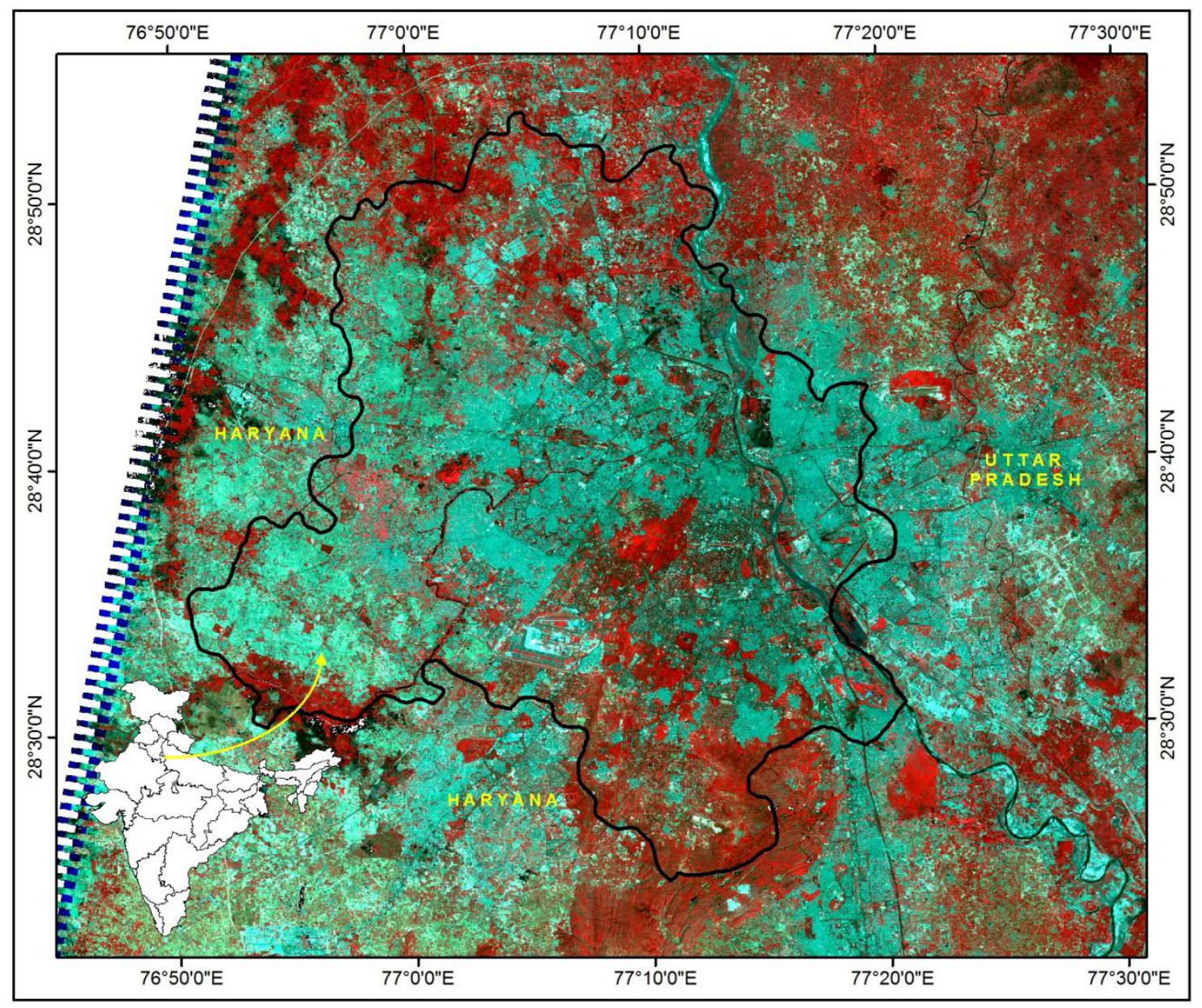

For the purpose of governance and management, Delhi is divided into nine districts and 27 tehsils/sub-divisions. According to the Census of India in 2011 [41], the Delhi grew from 0.4 million people in 1901 to 16.75 million in 2011, having population density of 11,297 persons per $\mathrm{km}^{2}$. Delhi accounted for urban population of $52.76 \%$ in 1901 that rose to $82.4 \%$ in $1951,93 \%$ in 2001 and $97.5 \%$ in 2011. Delhi enjoys the status of the principal administrative city of India and therefore is a hub of a range of governmental organizations, residential colonies, service and educational facilities and also industrial activities. Delhi has healthy forests and tree cover in its different parts and especially in its center, i.e., India Gate, Delhi Cantonment, Rashtrapati Bhawan and adjoining areas and Central-North Delhi ridge forest [42]. According to the FSI [40], the total forest cover of Delhi is $176.2 \mathrm{~km}^{2}$ (11.88\% of geographical area) and $120 \mathrm{~km}^{2}$ tree cover (8.09\% of geographical area). The vegetation on the ridge is thorny scrub type representing semi-arid conditions.

\section{Database and Methods}

Landsat Thematic Mapper (TM) 5 satellite images were used extensively to understand and interpret the inter-seasonal variations in thermal properties of land surface in Delhi. The satellite 
images were downloaded from the website of United States Geological Survey (USGS) [43] which are freely available to the users (Table 1). The Landsat 5 satellite following a sun-synchronous, near-polar path revolves around the earth at an altitude of $705 \mathrm{~km}$ with 16 days temporal resolution. It overpasses Delhi at local time of approximately 10:30 am. Landsat 5 provides TM images with seven bands; three in visible (Band 1-3) and one in near infrared (Band 4) regions and two in middle infrared (Band 5 and 7) having spatial resolution of $30 \mathrm{~m}$ and one thermal infrared band (Band 6) in $120 \mathrm{~m}$ spatial resolution. Since the spatial resolution of thermal band is high, Landsat images are well-suited for investigation in analyzing dynamics of LST and their relations with land use/cover [20,22,44].

Table 1. Details of acquired and used satellite images [43].

\begin{tabular}{cccccc}
\hline Satellite & Sensor & Acquisition date & Path and row & Spatial resolution * & Cloud cover \\
\hline Landsat 5 & TM & 16 January 2011 & $146 / 040$ & $120 \mathrm{~m}$ & $6 \%$ \\
Landsat 5 & TM & 5 March 2011 & $146 / 040$ & $120 \mathrm{~m}$ & $1 \%$ \\
Landsat 5 & TM & 8 May 2011 & $146 / 040$ & $120 \mathrm{~m}$ & $0 \%$ \\
Landsat 5 & TM & 29 September 2011 & $146 / 040$ & $120 \mathrm{~m}$ & $1 \%$ \\
\hline
\end{tabular}

* Resample to $30 \mathrm{~m}$.

Keeping in mind the objectives of the study, four satellite images from the same year, i.e., 2011 representing four different seasons were selected. Images from same year facilitated effective as well as rational comparability. The satellite images selected for the study are of 16 January 2011, 5 March 2011, 8 May 2011 and 29 September 2011 corresponding to winter, spring, summer and autumn seasons, respectively. The chief consideration was to opt for cloud free images.

The minimum temperature of Delhi in winters ranges between $1{ }^{\circ} \mathrm{C}$ and $4{ }^{\circ} \mathrm{C}$. Due to low wind speed there is atmospheric stability [45] and the lowest temperatures are observed in the month of January. Hence, the 16 January 2011 scenario represents the pattern adequately. The 5 March 2011 image corresponds to the spring season, characterized by pleasant weather with warm days and cool nights and low humidity. Following this is the hot summer season where the temperature soars to above $45^{\circ} \mathrm{C}$. June is the hottest month, interspersed with infrequent dust storms and frequent thunderstorms; however no image for June 2011 was available. Thus, the image of 8 May 2011 was used representing summers. By the end of June, the south westerly monsoonal winds arrive in Delhi marking the onset of rainy season. Over $80 \%$ of rainfall occurs during this season, with August being the rainiest month. The heat as well as the humidity is extremely high till September. Due to dense cloud cover, appropriate clear satellite images of this season are unavailable. However, the image of 29 September 2011 is well-representative of the withdrawal of rainy season and beginning of autumn season.

\section{Image Pre-Processing}

The downloaded images were pre-processed involving radiometric and geometric corrections to make them usable. To extract the surface temperature, three main steps were followed (Figure 2). 
Figure 2. Methodological framework showing steps of processing of Landsat thermal satellite data and analysis of surface temperature patterns.

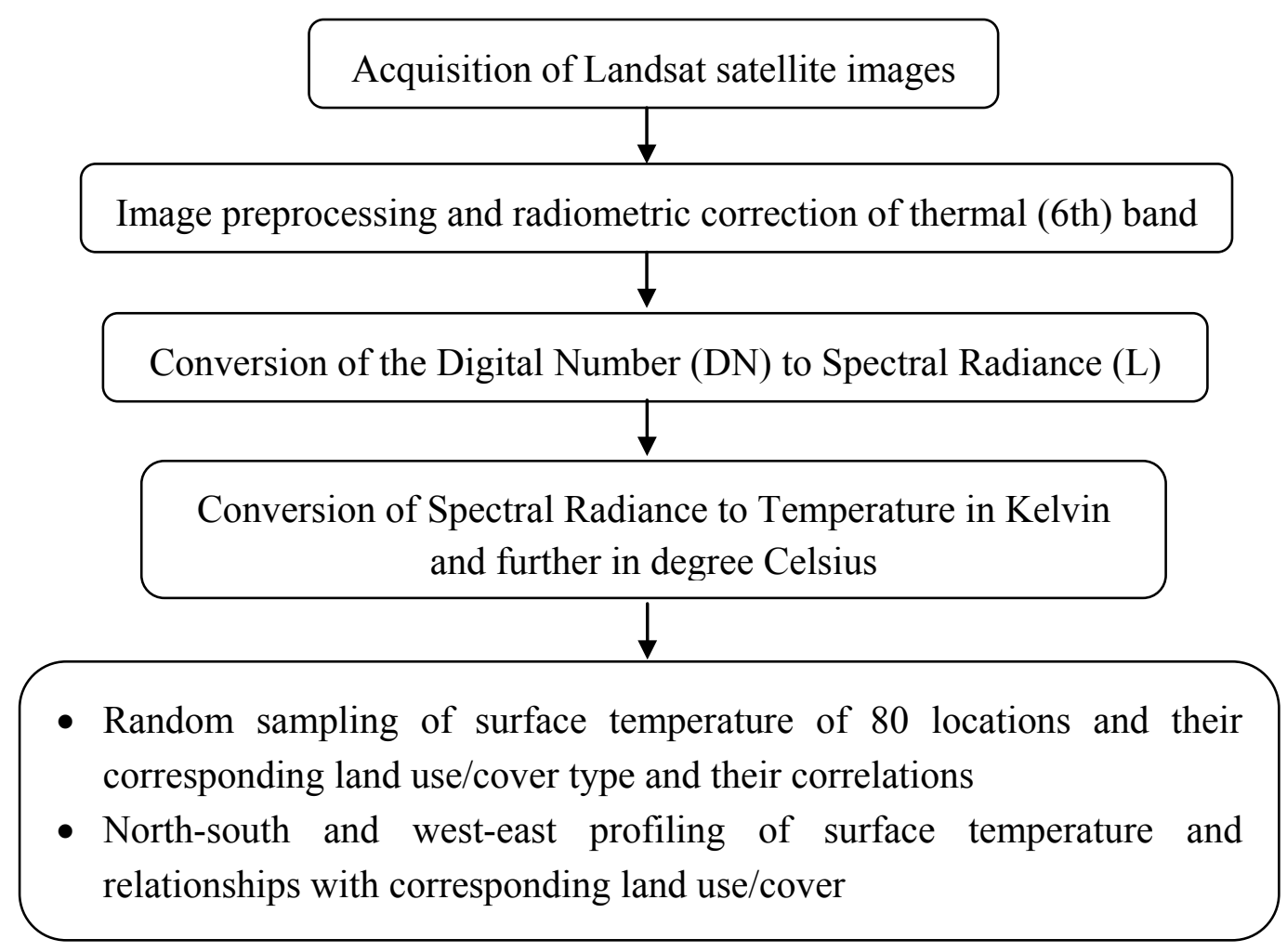

The first step is conversion of the Digital Number to Spectral Radiance [46]. The second being conversion of Spectral Radiance to temperature in Kelvin and the third is conversion of temperature in Kelvin to Celsius scale [34]. The steps are well described in Landsat 7 Science Data Users Handbook [47], Murayama and Lwin [48] and Chander et al. [49] which are as follows:

Step 1. Conversion of the Digital Number (DN) to Spectral Radiance (L):

$$
L_{\lambda}=L M I N+(L M A X-L M I N) \times D N / 255
$$

where $\mathrm{L}_{\lambda}=$ Spectral radiance; $\mathrm{LMIN}=1.238 ; \mathrm{LMAX}=15.600$; and $\mathrm{DN}=$ Digital Number.

Step 2. Conversion of Spectral Radiance to Temperature in Kelvin:

$$
T_{\mathrm{B}}=K_{2} / \operatorname{In}\left(\left(K_{1} / L_{\lambda}\right)+1\right)
$$

where $K_{1}=$ Calibration Constant 1 (607.76); $K_{2}=$ Calibration Constant 2 (1260.56) for thermal band of $\mathrm{TM}$ data; and $T_{\mathrm{B}}=$ Surface Temperature.

Step 3. Conversion of Kelvin to Celsius:

$$
T_{\mathrm{B}}\left({ }^{\circ} \mathrm{C}\right)=T_{\mathrm{B}}-273(\mathrm{~K})
$$

These three steps were repeated for all the four images. The temperature in Celsius scale ranged from $10.4{ }^{\circ} \mathrm{C}$ to $48{ }^{\circ} \mathrm{C}$, which was classified in 19 classes at $2^{\circ}$ class intervals. In order to establish the relationship between LST and corresponding land use/cover type, 80 sample points were selected randomly from different land use/cover types in the study area (Figure 3). About 11-13 samples were selected from each land use/cover types, e.g., urban and rural built-up land, agriculture, lakes and the 
Yamuna River, vegetations and sand bars. The thermal characteristics of these 80 locations are studied across the seasons. The average temperature of each land use/cover category for each season was calculated using the formula of simple arithmetic mean. The range of temperature was also estimated by calculating the difference of highest and lowest temperature of respective land use/cover in each season and for summers and winters. Further, to investigate on the spatial pattern of LST, west-east and north-south profiles have been plotted in Delhi for all the four seasons (Figure 3). The north-south profile covered 1826 pixels, whereas the west-east profile covered 1590 pixels. The major land use/cover types were plotted on $x$ axis and surface temperature on $y$ axis to effectively represent their spatial relationships.

Figure 3. Location of sample sites and profile lines (north-south and west-east) for comparison of surface temperatures in different seasons.

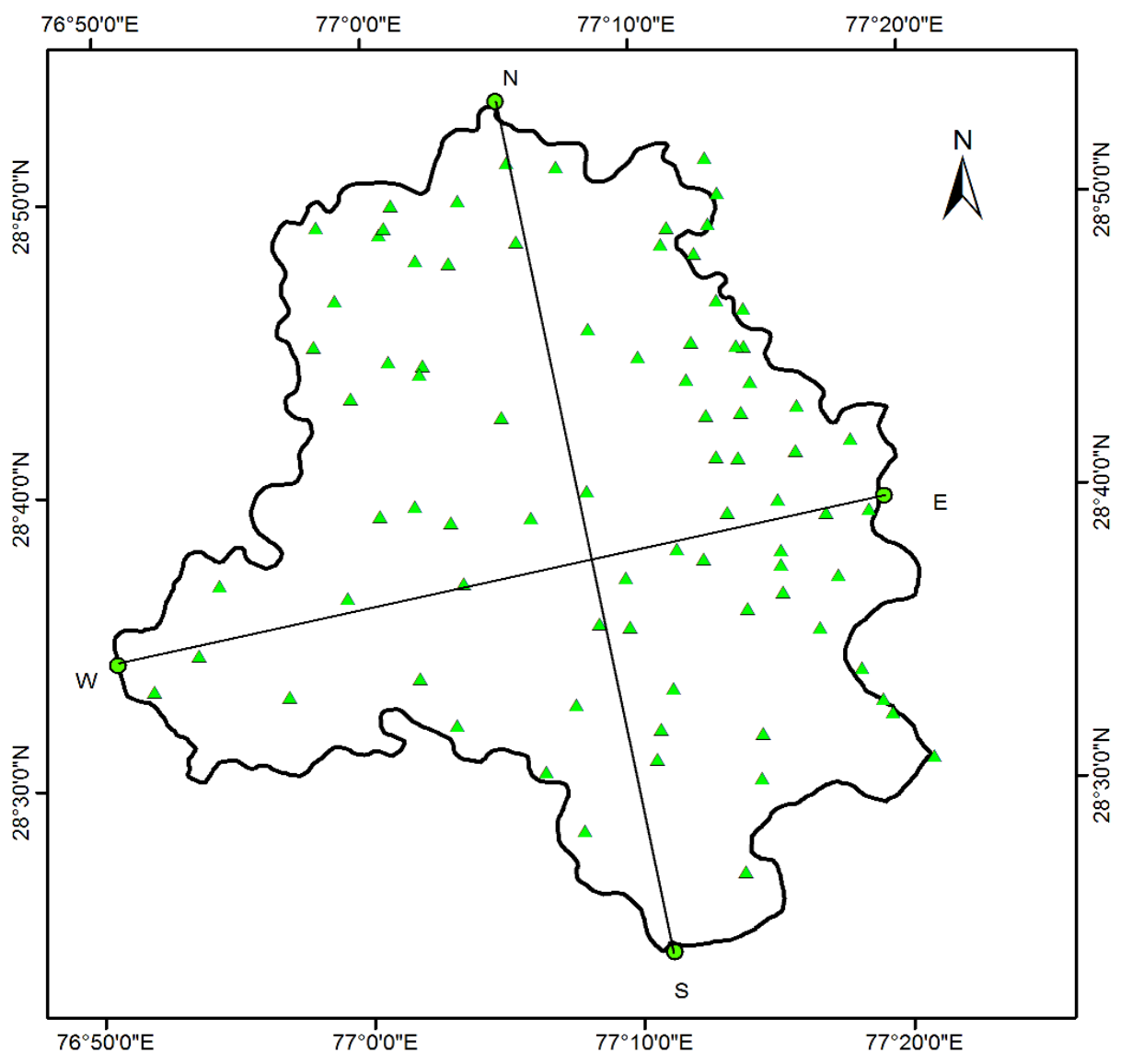

\section{Results and Discussion}

The seasonwise changes of spatial patterns of surface temperature are explored in relation to general land use/cover patterns through the surface temperature maps (Figure 4) extracted from the thermal band (Band 6) of Landsat TM 5 images for the four seasons. The general understanding of land use/cover information has been derived from visual inspection of tone and color of satellite image of study area (Figure 1), Google Earth and a previous study by Sharma [50]. The urban and rural built-up land cover is about 38\% area of Delhi. The built-up land is largely concentrated in central, south-eastern and eastern parts of study area. A few pockets are also found in the northern Delhi. Agriculture is practiced on about $34 \%$ of the total area of Delhi, which is largely concentrated in 
northern, western, south-western and extremely southern parts of Delhi. There are seasonal changes in the agricultural activities. During the summer months, the agricultural land is left fallow, while the rest of the year there are different crop varieties depending on the season. Agriculture is also practiced along the Yamuna River, that divides the study area in two parts east and west Delhi. The water bodies (lakes) are well distributed in north, south-west and south Delhi and cover very little area, i.e., $8.51 \mathrm{~km}^{2}$ [51]. Delhi has healthy forests and tree cover. As per the estimates of FSI [40], the forest and tree cover account for about 20\% area; whereas Sharma [50] reveals that vegetation cover about $14 \%$ area in Delhi. We have added open spaces [50] that are characterized by grassy patches to vegetation cover. The sand bars are only found along the Yamuna River (Figure 1).

Figure 4. Inter-seasonal variations of spatial patterns of surface temperature in Delhi: (a) winter; (b) spring; (b) summer; and (d) autumn.
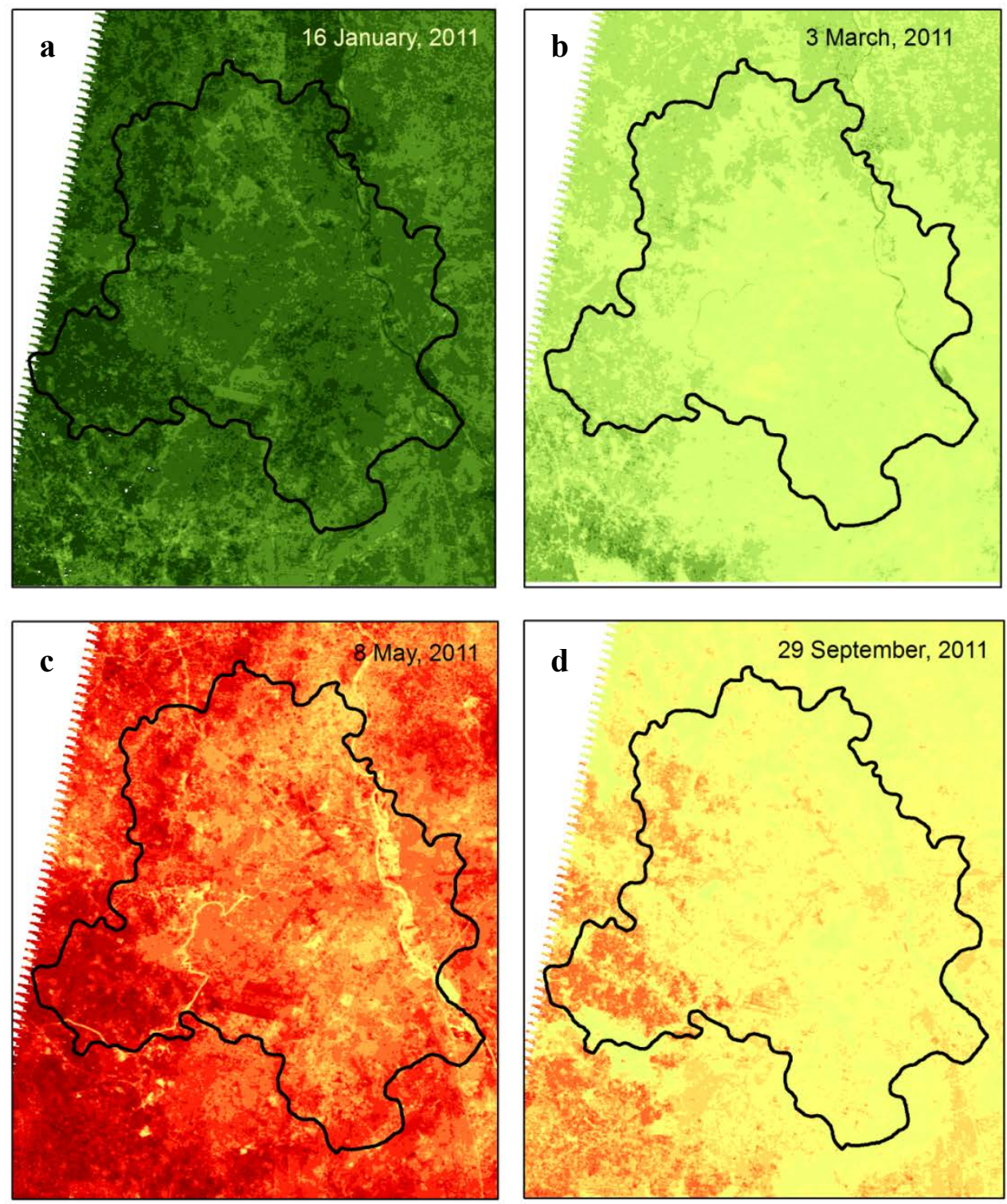

Temperature $\left({ }^{\circ} \mathrm{C}\right)$

\begin{tabular}{|c|c|c|c|c|c|c|}
\hline $10.4-12$ & $16.1-18$ & $22.1-24$ & $28.1-30$ & $34.1-36$ & $40.1-42$ & $46.1-48$ \\
\hline $12.1-14$ & $18.1-20$ & $24.1-26$ & $30.1-32$ & $36.1-38$ & $42.1-44$ & \\
\hline $14.1-16$ & $20.1-22$ & $26.1-28$ & $32.1-34$ & $38.1-40$ & $44.1-46$ & \\
\hline
\end{tabular}


Seasonwise spatial distribution of surface temperature suggests that January, representing the coldest month of the year, registered the lowest surface temperatures. The highest and lowest temperatures observed in winters (January) are $10.4{ }^{\circ} \mathrm{C}$ and $17{ }^{\circ} \mathrm{C}$, respectively. The lowest temperature $\left(10.4-13{ }^{\circ} \mathrm{C}\right)$ has been observed in the south-western, north and north-western parts of study area, which are predominantly under agricultural land and rural built-up use/cover. The water bodies including lakes, which are well-distributed in study area and dominate the peripheral areas where also record very low temperatures $\left(10.4-13{ }^{\circ} \mathrm{C}\right)$. The temperature of the Yamuna River is also recorded very low. The rocky ridge with some forest patches in the southern parts of Delhi also shows lowest surface temperature conditions. The highest temperatures of the season are seen in the open land of Delhi airport area (south Delhi), land under construction and developmental activities of north Delhi and sand bars along the Yamuna River $\left(17^{\circ} \mathrm{C}\right)$. The urban built-up land, which dominates the central and eastern parts of Delhi indicate moderate temperature $\left(13-15^{\circ} \mathrm{C}\right)$ conditions. The rural built-up land represents temperature condition akin to urban built-up land (Figure 4a).

Overall high temperatures have been recorded in the spring season in all parts of the study area, as compared to winters. However, the patterns of surface temperature are similar to winter season. The highest and lowest temperatures recorded for the season are about $17{ }^{\circ} \mathrm{C}$ and $26{ }^{\circ} \mathrm{C}$. Lower temperatures $\left(18-20{ }^{\circ} \mathrm{C}\right.$ ) are recorded in north western and south western parts of Delhi dominated by agriculture and rural built-up land. The water bodies record even lower temperature $\left(17^{\circ} \mathrm{C}\right)$. The moderate temperatures $\left(21-23{ }^{\circ} \mathrm{C}\right)$ are noticed for urban built-up land, which dominate the central and east Delhi. The open area of the airport and some parts of urban built-up land record the highest temperatures in this season (Figure $4 b$ ).

The temperatures ascend sharply in summers and the pattern of spatial distribution of temperature transforms significantly. Only the water bodies (drains, the Yamuna River and lakes), ridge forests and other forests patches record lower temperatures $\left(28-30^{\circ} \mathrm{C}\right)$. The south-western and north-western parts of Delhi, that are mainly the rural built-up and agricultural land, experience highest temperatures (up to $45{ }^{\circ} \mathrm{C}$ ). The open areas of Delhi airport also experience intense heating (about $43{ }^{\circ} \mathrm{C}$ ). It is important to note that areas with highest temperature in summer, experienced lowest temperature in winter, thus observing the highest temperature range as compared to the other areas. The central, southern and eastern parts of Delhi (mainly urban built-up land) observe moderate temperature $\left(34-39{ }^{\circ} \mathrm{C}\right)$. The temperature in summers ranges from $28{ }^{\circ} \mathrm{C}$ to about $45{ }^{\circ} \mathrm{C}$ (Figure $4 \mathrm{c}$ ). The details of highest and lowest temperatures associated with each land use/cover types are mentioned in Table 2.

In autumn, western portions also bear elevated temperatures, with the maxima reached in south-west Delhi. Central, northern and eastern Delhi are relatively cooler, with the exception of a few patches (Figure 4d). Similar results were revealed for LST in the autumn season over Delhi by Mallick et al. [26] using a Landsat TM image of 25 October 2009. According to them, the LST ranged from $22.2{ }^{\circ} \mathrm{C}$ to $46{ }^{\circ} \mathrm{C}$ with west and south-western part of Delhi exhibiting the highest surface temperature $\left(35-44^{\circ} \mathrm{C}\right)$. Kant et al. [21] analyzed LST using ASTER datasets for Delhi using the 22 September 2003 images and observed parallel results. 
Table 2. Details of land use/cover, number of samples temperature taken from land use/cover and seasonwise maximum and minimum average temperature $\left({ }^{\circ} \mathrm{C}\right)$. Source: Calculated from Landsat TM 5 thermal band.

\begin{tabular}{|c|c|c|c|c|c|c|c|c|c|c|}
\hline \multirow{2}{*}{ Land use/cover } & \multirow{2}{*}{$\begin{array}{l}\text { Area } \\
(\%) *\end{array}$} & \multirow{2}{*}{$\begin{array}{c}\text { Samples } \\
\text { (No.) }\end{array}$} & \multicolumn{2}{|c|}{16 January } & \multicolumn{2}{|c|}{3 March } & \multicolumn{2}{|c|}{8 May } & \multicolumn{2}{|c|}{29 September } \\
\hline & & & Max. & Min. & Max. & Min. & Max. & Min. & Max. & Min. \\
\hline Agriculture & 35.4 & 11 & 16 & 11 & 23 & 18 & 43 & 30 & 35 & 25 \\
\hline Lakes & \multirow{2}{*}{1.4} & 11 & 13 & 11 & 21 & 18 & 35 & 27 & 29 & 25 \\
\hline The Yamuna River & & 11 & 15 & 12 & 22 & 17 & 33 & 27 & 27 & 24 \\
\hline Sand & - & 11 & 17 & 11 & 24 & 17 & 39 & 29 & 33 & 24 \\
\hline \multirow{2}{*}{$\begin{array}{l}\text { Urban built-up } \\
\text { Rural built-up }\end{array}$} & \multirow{2}{*}{38.2} & 11 & 14 & 13 & 23 & 21 & 37 & 34 & 30 & 28 \\
\hline & & 12 & 14 & 12 & 22 & 20 & 39 & 35 & 31 & 30 \\
\hline Vegetation $* *$ & 24 & 13 & 13 & 11 & 22 & 18 & 34 & 30 & 27 & 25 \\
\hline
\end{tabular}

* Sharma, 2013; ** Vegetation merged with open land in order to make the land use/cover categories comparable.

On the basis of analysis of 80 samples points selected for all the four seasons, it is found that the overall average surface temperature is lowest in January and highest in May. The March and September observe moderate temperature; however the average temperature of September is more than that of March (Table 3). In winters, the lowest average temperature is observed for agriculture, lakes and vegetation cover; the moderate temperature for urban and rural built-up area, the Yamuna River and highest temperature for sand bars along the river. In spring, a relatively higher average temperature is recorded for all land use/cover categories. The analysis of average temperature of summer season reveals significant variations across the land use/cover categories. The highest average temperature is observed in agricultural and rural built-up land, i.e., $38{ }^{\circ} \mathrm{C}$ and $36{ }^{\circ} \mathrm{C}$, respectively. Urban built-up and sand bars along the Yamuna River indicate relatively lower temperatures, i.e., $34{ }^{\circ} \mathrm{C}$ and $35^{\circ} \mathrm{C}$. The lowest temperature is recorded for vegetation, lakes and the Yamuna River $\left(30-32^{\circ} \mathrm{C}\right)$. In the autumn, a relatively lower average temperature is recorded for all the land use/cover types as compared to summers; however the spatial pattern remains unchanged.

Table 3. Seasonwise average temperature across the land use/cover types. Source: Calculated from Landsat TM 5 thermal band.

\begin{tabular}{ccccc}
\hline Land use/cover & 16 January & 3 March & 8 May & 29 September \\
\hline Agriculture & 12 & 20 & 38 & 31 \\
Lakes & 12 & 19 & 31 & 26 \\
Sand & 15 & 21 & 34 & 29 \\
The Yamuna River & 13 & 19 & 30 & 25 \\
Urban built-up & 13 & 21 & 35 & 30 \\
Vegetation & 12 & 21 & 32 & 26 \\
Rural built-up & 13 & 21 & 36 & 30 \\
\hline
\end{tabular}

It is interesting to note that the range of surface temperatures for different land use/cover types varies significantly across four seasons (Figure 5). 
Figure 5. Inter-seasonal variation of surface temperature across land use/cover categories:

(a) the Yamuna River; (b) lakes; (c) urban built-up; (d) rural built-up; (e) agriculture; (f) vegetation; and (g) sand.

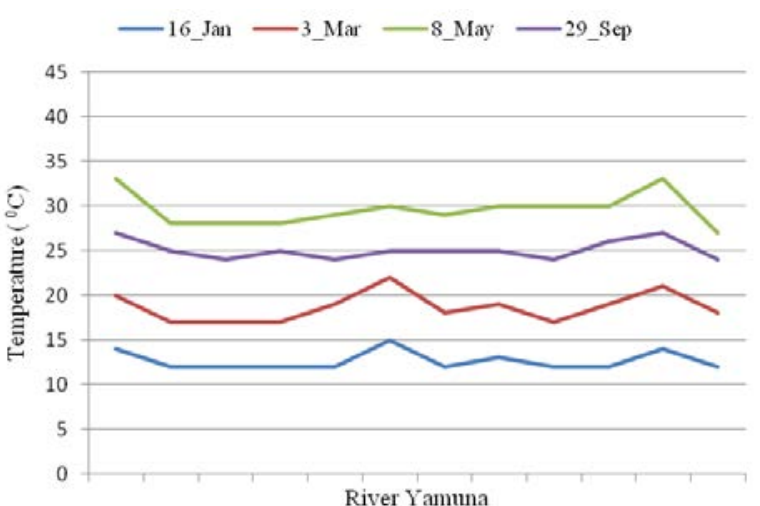

(a)

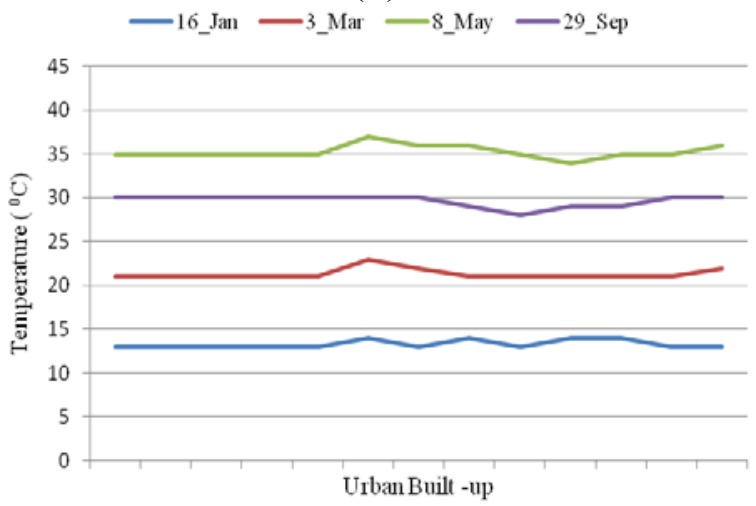

(c)

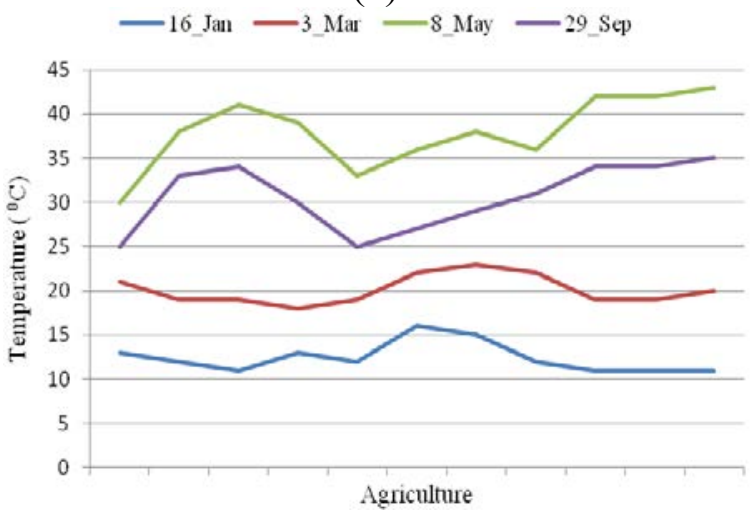

(e)

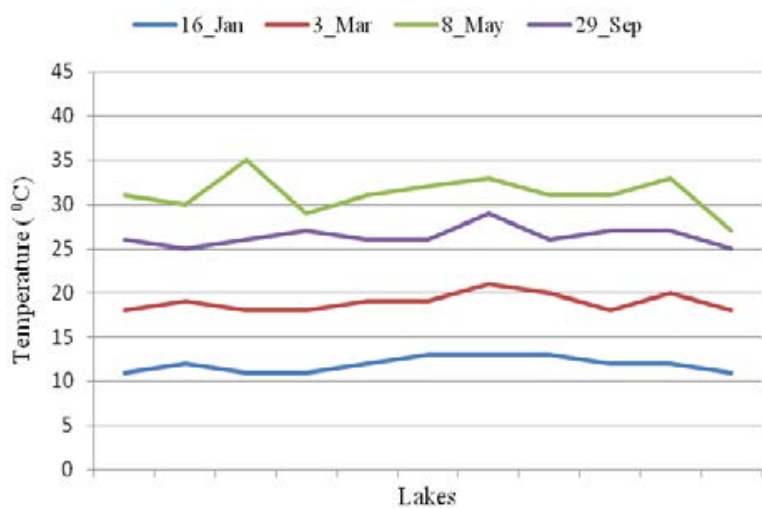

(b)

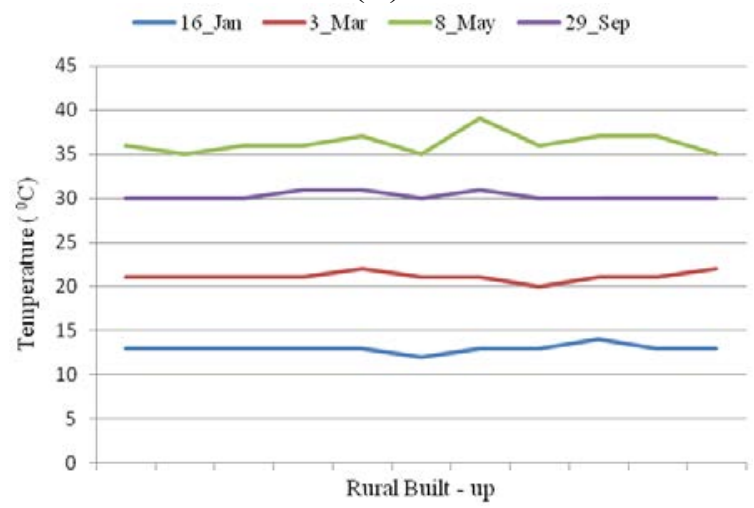

(d)

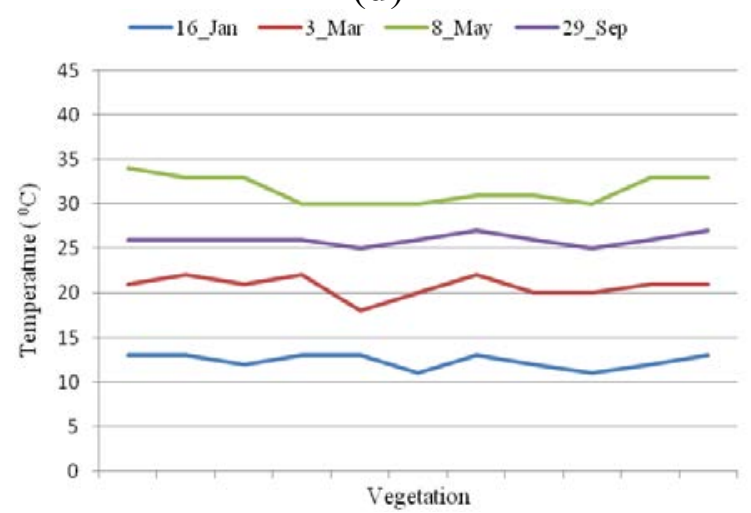

(f)

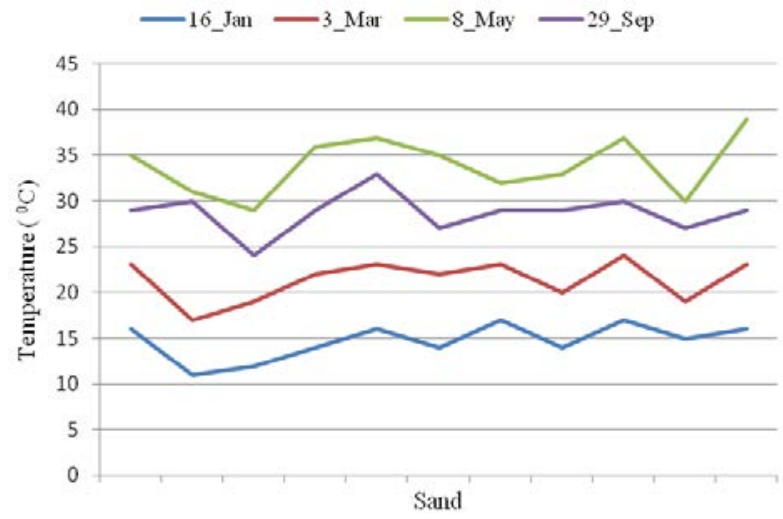

(g) 
The range is the difference between the highest and lowest temperature of the respective land use/cover in each season and for summers and winters. The analysis of range of average temperatures across the land use/cover types in different seasons reveals that it is merely $3{ }^{\circ} \mathrm{C}$ for winters $\left(12{ }^{\circ} \mathrm{C}\right.$ for agriculture, lakes and vegetation and $15{ }^{\circ} \mathrm{C}$ for sand bars) and $2{ }^{\circ} \mathrm{C}$ for spring $\left(19{ }^{\circ} \mathrm{C}\right.$ for lakes and the Yamuna River and $21{ }^{\circ} \mathrm{C}$ for sand bars, urban and rural built-up land and vegetation cover) but spectacularly high in summers, i.e., $8{ }^{\circ} \mathrm{C}\left(38{ }^{\circ} \mathrm{C}\right.$ for agriculture and $30{ }^{\circ} \mathrm{C}$ for the Yamuna River) and decreases in autumn with $6{ }^{\circ} \mathrm{C}\left(31{ }^{\circ} \mathrm{C}\right.$ for agriculture and $25{ }^{\circ} \mathrm{C}$ for the Yamuna River). The magnitude of the temperature difference between extreme winters and summers changes with the land use/cover types. The maximum temperature difference has been noted for agricultural land $\left(26^{\circ} \mathrm{C}\right)$ followed by rural built-up $\left(23^{\circ} \mathrm{C}\right)$ and urban built-up land $\left(22^{\circ} \mathrm{C}\right)$. Thus, the agricultural, rural and urban built-up land are heated and cooled quickly than other land cover types. The lakes, sand bars vegetation have lower temperature difference, i.e., $19{ }^{\circ} \mathrm{C}$, whereas the minimum difference has been observed in the Yamuna River.

The north-south and west-east profiling of surface temperature across Delhi was also attempted in order to find out the minor spatial differences of surface temperature and to further identify the UHIs in Delhi. On the $x$ axis, the land use/cover types have been mentioned for major peaks and troughs in the temperature profiles representing different seasons. In the north-south (Figure 6) and west-east (Figure 7) temperature profiles, a total of 1826 and 1590 pixels, respectively, were taken into consideration for the purpose. In general, there should be higher temperatures in the city core (built-up land) in comparison to the periphery dominated by agriculture, vegetation and rural areas as suggested by Zhang and Wang [7] based on ten cities in Guangdong Province of China. Such surface temperature conditions have been confirmed by Chen et al. [16] in case of the Pearl River Delta, Li et al. [52], Jiang and Tian [53] and Ding and Shi [22] for Shanghai. However, Delhi does not possess this pattern of surface temperature that is in contrast to the general understanding of UHIs (Figures 6 and 7). The built-up areas in central Delhi do not indicate highest temperature conditions. Instead the agricultural areas, which are left fallow in the summer season, possess the highest temperatures.

The study of temperature profiles reveals that generally the western parts of Delhi experience the highest surface temperature in summers and autumn seasons and lowest in winters and spring seasons. The area is mainly dominated by agriculture and small rural built-up land. The central Delhi (main city) and eastern parts of Delhi (mainly built-up) show lower temperatures as compared to west Delhi in the summer and autumn seasons. In general, the highest peaks in the profiles of summer and autumn seasons are related to agricultural land, followed by the higher peaks associated to urban and rural built-up lands. The troughs are associated with water bodies (the Yamuna River and drains) and vegetation. On the contrary, the surface temperature recorded in central and east Delhi is higher than that observed in west Delhi during the winters and spring. The lowest temperature is associated with agriculture and water bodies and higher temperature to urban built-up land. It suggests the presence of a UHI in the winter season and not in the summers (Figure 6). 
Figure 6. West-east gradient/profile of surface temperature and major land use/cover across Delhi. A-Rural built-up; B-Agriculture; C-Drain; D-Urban built-up; E-Vegetation; and $\mathrm{F}$ - The Yamuna River.

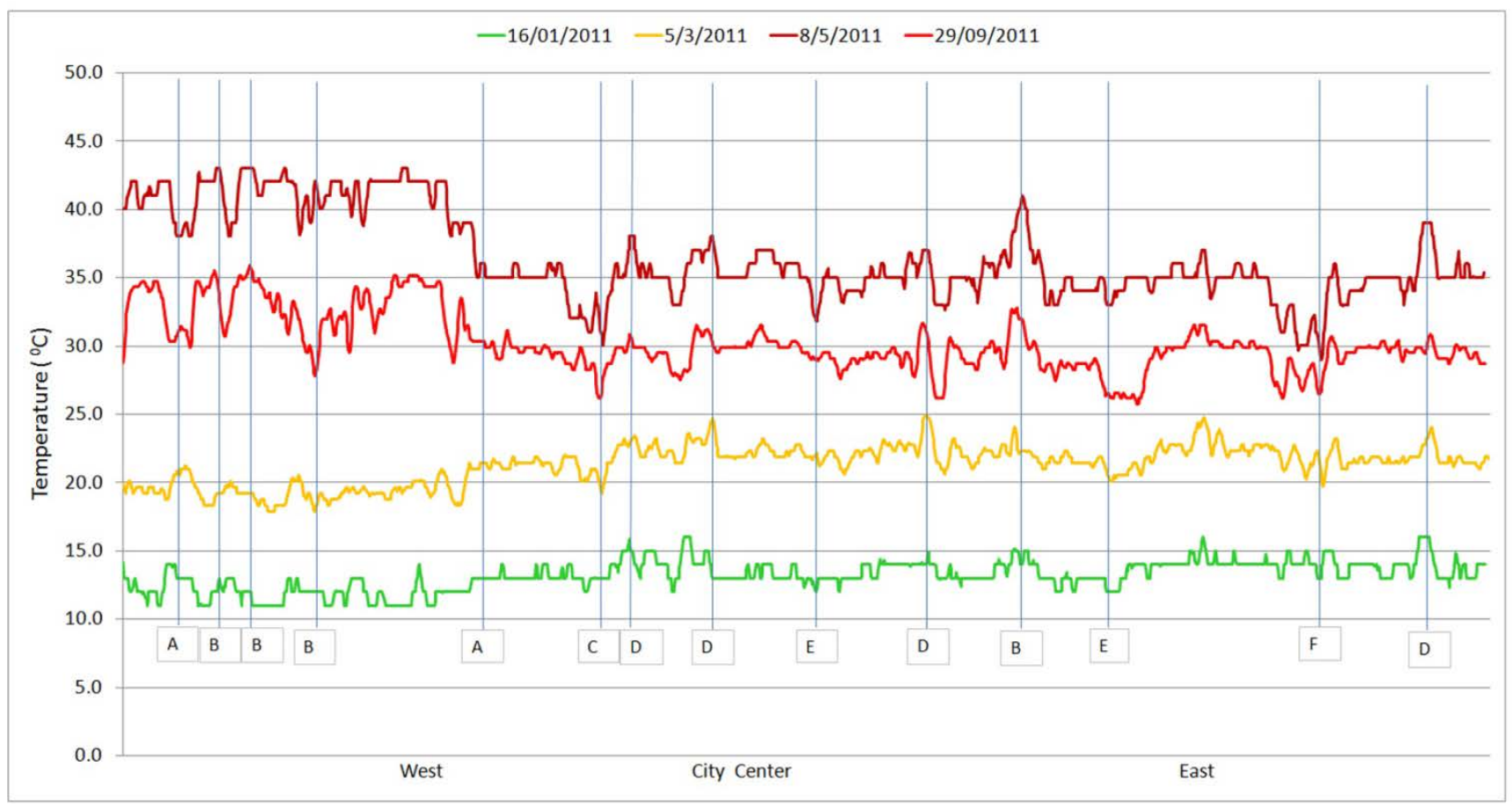

Figure 7. North-south profile of surface temperature and major land use/cover across Delhi. A-Rural built-up; B-Agriculture; C-Drain; D-Urban built-up; E-Vegetation; $\mathrm{F}$ - the Yamuna River; G-Rocky ridge; and $\mathrm{H}$ - Lakes.

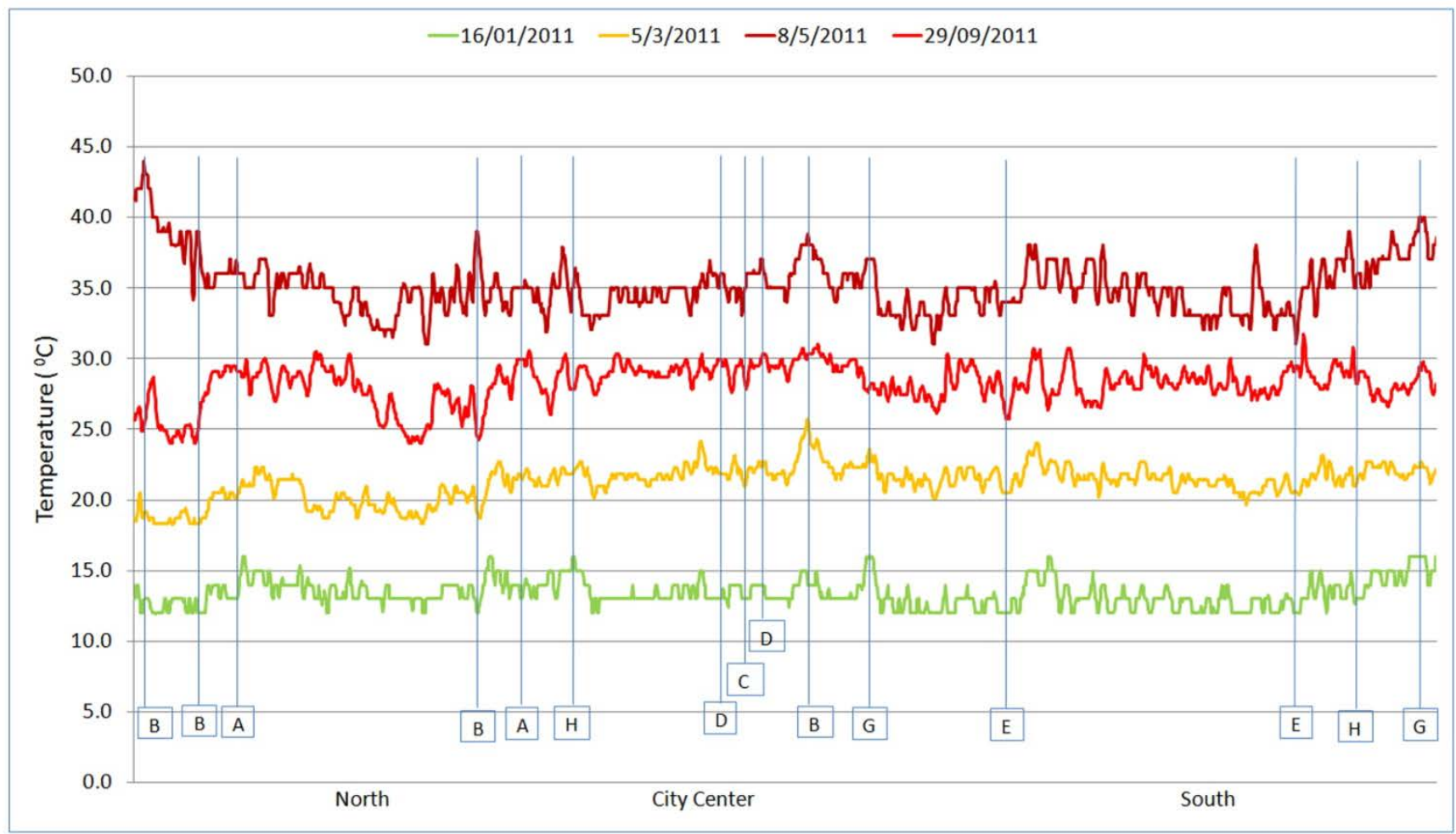


The temperature profile for north-south intersection shows a large variation of temperature across seasons, accompanied with sharp temperature peaks and troughs. In the summer and autumn seasons, the highest temperatures are observed in the extreme northern and southern parts of Delhi, which are predominantly agricultural and rocky ridge areas. The central parts (urban built-up) of Delhi show relatively lower temperatures than the extreme north and south. During the winters and spring, the lowest temperatures are related to those areas which experienced the highest temperature in summers, i.e., northern Delhi that is dominated by agricultural land use. Central Delhi (city) shows a relatively higher temperature. In general, the highest peaks are related to agriculture and rocky ridges and relatively lower peaks to urban and rural built-up land. The water bodies and vegetation show lower temperatures. During the winters and spring, the lower temperature is related to agriculture and the Yamuna and higher to built-up land, vegetation cover, etc. (Figure 7).

The study reveals that Delhi does not have a strong presence of a UHI in any season. The highest LST is not related with urban built-up land in Delhi, as noted in other cities across the globe, e.g., Yue et al. [8], Jiang and Tian [53], Ding and Shi [22] for Shanghai, and Hung et al. [20] for Asian cities, and Benali et al. [28] for Portugal. It may be associated with many factors, including the presence of healthy forests and tree cover in the center of the city and in other parts, low building heights, location of the Yamuna River, etc. As per the estimates of FSI [40], Delhi has healthy forests and tree cover (about 20\%), which are well distributed in city in patches. The Aravalli ridge, covered with thick forest cover, is well extended from south Delhi to the city center. The healthy forests and tree cover and especially the ridge forests act as thermal moderator and cooling agent in the climate of Delhi [42]. Vegetation cover acts as heat sinks [38] and plays an important role in mitigating the climate of local and adjoining areas, hence controlling the extreme heating of concerned areas. The relationships of LST and NDVI-vegetation [8-10,25] suggest that lower temperatures are associated with healthy forest cover. In Delhi, the average temperatures of areas covered with vegetation are close to that of water bodies, indicating their crucial role in reducing the temperature of the city.

The overall height of buildings in Delhi is low as compared to other cities of the world, where the presence of a UHI has been confirmed, e.g., Atlanta [4] and Shanghai [8,33,36]. High rise buildings trap the solar radiation and reduce the air circulation. The air circulation balances the heat, which is hindered by high rise buildings that raise the overall temperature in concerned areas. The spacing of buildings and building material are other phenomenon related to urban geometry that also influence the LST $[6,14]$.

The location of the Yamuna River and a large number of water bodies surrounded by vegetation cover in study area may also lead to comparatively lower LST of the urban built-up land. The Yamuna is a perennial river that passes through Delhi in such a way that it divides it in two parts (east Delhi and rest of the Delhi). The water acts as a heat moderator, since it has relatively high latent heat of vaporization and heat storing capacity as compared to solid land parts.

The highest and lowest temperatures are found in agricultural land in the summer and winter season, respectively. The agricultural land is left fallow in summers, and during the rest of the year, there are different crops depending on the season. The high range of surface temperatures of agricultural land may be attributed to the soil properties therein. The soil in Delhi is sandy, which is quickly heated in summers and the temperature is recorded as the highest, while in winters, they are cooled quickly as a result of radiational cooling at night. The winter temperature is recorded relatively 
high in the urban built-up land as compared to other land use/cover types. This phenomenon may be attributed to the impervious nature of the land surface and low vegetation cover. Similar results have been derived by Yuan and Bauer [38] for the Twin Cities, Minnesota, USA, metropolitan area, Li et al. [52] for Shanghai, China, and Deng and Wu [54] for the four cities of Washington, Ozaukee, Milwaukee and Waukesha in USA. The strong linear relationship between LST and impervious surface and relatively weak relationships between LST and NDVI have been noted in the above studies.

\section{Conclusions}

There is significant diversity in the temporal and spatial pattern of distribution of temperature in Delhi. While the coolest month reveals a low temperature in all land use/cover types, the summer month has the highest temperature. The difference between maximum and minimum temperature for the sandy areas and agricultural land is highest for all seasons, largely corresponding to the peripheral areas of Delhi. This difference is lowest for water bodies and vegetation cover mainly due to albedo factor. The west-east profile of temperature reveals similar results. Even the north-south temperature gradient does not reflect visible heat islands in any season. The presence of a perennial river flowing across the middle of the city has a significant influence in weakening the creation of prominent heat islands. Added to this is the role of the vegetated Delhi ridge. The north-south and west-east temperature gradient demonstrate that the core of Delhi has a much lower temperature than its periphery and thus there is a weak UHI phenomenon.

\section{Acknowledgments}

The authors are thankful to Xiangzheng Deng for expert comments and to Suraj Mal for his critical comments. We also acknowledge the reviewers of our paper for their valuable inputs towards the improvement of the quality of the research article.

\section{Conflicts of Interest}

The authors declare no conflict of interest.

\section{References}

1. Singh, R.B.; Murai, S. Space Technology for Sustainable Development; Oxford \& IBH Publisher: New Delhi, India, 1998; p. 368.

2. Singh, R.B.; Kumar, D. Remote sensing and GIS for land use/cover mapping and integrated land management: Case from the middle Ganga plain. Front. Earth Sci. 2012, 6, 167-176.

3. Valsson, S.; Bharat, A. Urban Heat Island: Cause for Microclimate Variations. Architecture-Time Space \& People, April 2009, 21-25.

4. Lo, C.P.; Quattrochi, D.A. Land-use and land-cover change, urban heat island phenomenon, and health implications: A remote sensing approach. Photogramm. Eng. Remote Sens. 2003, 69, 1053-1063.

5. United Nations Human Settlements Programme. Cities and Climate Change: Global Report on Human Settlements; Earthscan: London, UK; Washington, DC, USA, 2011. 
6. Voogt, J.A.; Oke, T.R. Thermal remote sensing of urban climates. Remote Sens. Environ. 2003, $86,370-384$.

7. Zhang, J.; Wang, Y. Study of the Relationships between the spatial extent of surface urban heat islands and urban characteristic factors based on Landsat ETM+ Data. Sensors 2008, 8, 7453-7468.

8. Yue, W.; Xu, J.; Tan, W.; Xu, L. The relationship between land surface temperature and NDVI with remote sensing: Application to Shanghai Landsat $7 \mathrm{ETM}+$ data. Int. J. Remote Sens. 2007, $28,3205-3226$.

9. Gallo, K.P.; Mcnab, A.L.; Karl, T.R.; Brown, J.F.; Hood, J.J.; Tarpley, J.D. The use of a vegetation index for assessment of the urban heat island effect. Int. J. Remote Sens. 1993, 14, 2223-2230.

10. Owen, T.W.; Carlson, T.N.; Gillies, R.R. An assessment of satellite remotely sensed land cover parameters in quantitatively describing the climatic effect of urbanization. Int. J. Remote Sens. 1998, 19, 1663-1681.

11. Goward, S.N. Thermal behavior of urban landscapes and the urban heat island. Phys. Geogr. 1981, 2, 19-33.

12. Li, Z.H.; Deng, X.Z.; Shi, Q.L.; Ke, X.L.; Liu, Y.C. Modeling the impacts of boreal deforestation on the near-surface temperature in European Russia. Adv. Meteorol. 2013, 2013, doi:10.1155/2013/486962.

13. Deng, X.Z.; Huang, J.K.; Lin, Y.Z.; Shi, Q.L. Interactions between climate, socio-economics, and land dynamics in Qinghai Province, China: A LUCD model-based numerical experiment. Adv. Meteorol. 2013, 2013, doi:10.1155/2013/297926.

14. Oke, T.R. The energetic basis of the urban heat island. Q. J. R. Meteorol. Soc. 1982, 108, 1-24.

15. Charabi, Y.; Bakhit, A. Assessment of the Canopy Urban Heat Island of a coastal arid tropical city: The case of Muscat, Oman. Atmos. Res. 2011, 101, 215-227.

16. Chen, X.L.; Zhao, H.M.; Li, P.X.; Yin, Z.Y. Remote sensing image-based analysis of the relationship between urban heat island and land use/cover changes. Remote Sens. Environ. 2006, 104, 133-146.

17. Mcpherson, E.G.; Nowak, D.; Heisler, G.; Grimmond, S.; South, C.; Grant, R.; Rowntree, R. Quantifying urban forest structure, function and value: The Chicago urban forest climate project. Urban Ecosyst. 1997, 1, 49-61.

18. Singh, R.B.; Fox, J.; Himiyama, Y. Land Use and Cover Change; Science Publishers Inc.: Enfield, NH, USA; Oxford \& IBH Publishing Company: New Delhi, India, 2001.

19. Stone, B.; Rodgers, M.O. Urban form and thermal efficiency: How the design of cities influences the urban heat island effect. J. Am. Plan. Assoc. 2001, 67, 186-198.

20. Hung, T.; Uchihama, D.; Ochi, S.; Yasuoka, Y. Assessment with satellite data of the urban heat island effects in Asian mega cities. Int. J. Appl. Earth Obs. Geoinf. 2006, 8, 34-48.

21. Kant, Y.; Bharath, B.D.; Mallick, J.; Atzberger, C.; Kerle, N. Satellite-based analysis of the role of land use/land cover and vegetation density on surface temperature regime of Delhi, India. J. Indian Soc. Remote Sens. 2009, 37, 201-214.

22. Ding, H.; Shi, W. Land-use/land-cover change and its influence on surface temperature: A case study in Beijing city. Int. J. Remote Sens. 2013, 34, 5503-5517. 
23. Şahin, M.; Yildiz, B.Y.; Şenkal, O.; Peştemalci, V. Modelling and remote sensing of land surface temperature in Turkey. J. Indian Soc. Remote Sens. 2011, 40, 399-409.

24. Weng, Q.; Dengshang, L.; Jacquelyn, S. Estimation of land surface temperature-Vegetation abundance relationship for urban heat island studies. Remote Sens. Environ. 2004, 89, 467-483.

25. Amiri, R.; Weng, Q.; Alimohammadi, A.; Alavipanah, S.K. Spatial-temporal dynamics of land surface temperature in relation to fractional vegetation cover and land use/cover in the Tabriz urban area, Iran. Remote Sens. Environ. 2009, 113, 2606-2617.

26. Mallick, J.; Singh, C.K.; Shashtri, S.; Rahman, A.; Mukherjee, S. Land surface emissivity retrieval based on moisture index from Landsat TM satellite data over heterogeneous surfaces of Delhi city. Int. J. Appl. Earth Obs. Geoinf. 2012, 19, 348-358.

27. Coll, C.; Caselles, V.; Valor, E.; Niclòs, R. Comparison between different sources of atmospheric profiles for land surface temperature retrieval from single channel thermal infrared data. Remote Sens. Environ. 2012, 117, 199-210.

28. Benali, A.; Carvalho, A.C.; Nunes, J.P.; Carvalhais, N.; Santos, A. Estimating air surface temperature in Portugal using MODIS LST data. Remote Sens. Environ. 2012, 124, 108-121.

29. Zaksek, K.; Ostir, K. Downscaling land surface temperature for urban heat island diurnal cycle analysis. Remote Sens. Environ. 2012, 117, 114-124.

30. Mallick, J.; Kant, Y.; Bharath, B.D. Estimation of land surface temperature over Delhi using Landsat-7 ETM. J. Indian Geophys. Union 2008, 12, 131-140.

31. Mohan, M.; Pathan, S.K.; Narendrareddy, K.; Kandya, A.; Pandey, S. Dynamics of urbanization and its impact on land-use/land-cover: A case study of megacity Delhi. J. Environ. Prot. 2011, 2, 1274-1283.

32. Roy, S.S.; Singh, R.B.; Kumar, M. An analysis of local spatial temperature patterns in the Delhi Metropolitan Area. Phys. Geogr. 2011, 32, 114-138.

33. Li, Y.Y.; Zhang, H.; Kainz, W. Monitoring patterns of urban heat islands of the fast-growing Shanghai metropolis, China: Using time-series of Landsat TM/ETM+ data. Int. J. Appl. Earth Obs. Geoinf. 2012, 19, 127-138.

34. Pandey, P.; Kumar, D.; Prakash, A.; Kumar, K.; Jain, V.K. A study of the summertime urban heat island over Delhi. Int. J. Sustain. Sci. Stud. 2009, 1, 27-34.

35. Weng, Q.; Yang, S. Managing the adverse thermal effects of urban development in a densely populated Chinese city. J. Environ. Manag. 2004, 70, 145-156.

36. Streutker, D.R. Satellite-measured growth of the urban heat island of Houston, Texas. Remote Sens. Environ. 2003, 85, 282-289.

37. Zhang, H.; Qi, Z.-F.; Ye, X.-Y.; Cai, Y.-B.; Ma, W.-C. Analysis of land use/land cover change, population shift, and their effects on spatiotemporal patterns of urban heat islands in metropolitan Shanghai, China. Appl. Geogr. 2013, 44, 121-133.

38. Yuan, F.; Bauer, M.E. Comparison of impervious surface area and normalized difference vegetation index as indicators of surface urban heat island effects in Landsat imagery. Remote Sens. Environ. 2007, 106, 375-386.

39. Central Pollution Control Board. Water Quality Status of Yamuna River (1999-2005); Ministry of Environment \& Forests, Government of India: New Delhi, India, 2006. 
40. Forest Survey of India. State of Forest Report; Ministry of Environment \& Forests: Dehradun, India, 2011.

41. Directorate of Census Operations. Provisional Population Totals, NCT of Delhi; Ministry of Home Affairs, Government of India: New Delhi, India, 2011.

42. Sejwar, C.; Mal, S. Conservation and management of forests in Delhi. In Natural Resources Management; Pandey, B.W., Ed.; Mittal Publication: New Delhi, India, 2005; pp. 429-438.

43. United States Geological Survey (USGS). Available online: www.earthexplorer.usgs.gov (accessed on 20 February 2013).

44. Sharma, R.; Joshi, P.K. Monitoring urban landscape dynamics over Delhi (India) using remote sensing (1998-2011) inputs. J. Indian Soc. Remote Sens. 2013, 41, 641-650.

45. Perrino, C.; Tiwari, S.; Catrambone, M.; Torre, S.D.; Rantica, E.; Canepari, S. Chemical characterization of atmospheric PM in Delhi, India, during different periods of the year including Diwali festival. Atmos. Pollut. Res. 2011, 2, 418-427.

46. Xiao, H.; Weng, Q. The impact of land use and land cover changes on land surface temperature in a karst area of China. J. Environ. Manag. 2007, 85, 245-257.

47. Landsat 7 Science Data Users Handbook; National Aeronautics and Space Administration (NASA): Washington, DC, USA, 2003. Available online: http://landsathandbook.gsfc.nasa.gov/pdfs/ Landsat7_Handbook.pdf (accessed on 22 August 2013).

48. Murayama, Y.; Lwin, K.K. Estimation of Landsat TM Surface Temperature Using ERDAS Imagine Spatial Modeler; University of Tsukuba: Ibaraki, Japan, 2010. Available online: http://giswin.geo.tsukuba.ac.jp/sis/tutorial/koko/SurfaceTemp/SurfaceTemperature.pdf (accessed on 23 August 2013).

49. Chander, G.; Markham, B.; Helder, D. Summary of current radiometric calibration coefficients for Landsat MSS, TM, ETM+ and EO-1 ALI sensors. Remote Sens. Environ. 2009, 113, 893-903.

50. Sharma, R. Development and Behaviour of Surface Urban Heat Island (SUHI) in Semi-Arid Conditions of Delhi. Ph.D. Thesis, TERI University, New, Delhi, India, December 2013.

51. Singh, R.B.; Gahlot, S.; Singh, A. Ecohydrological Perspectives of Declining Water Sources and Quality in Traditional Water Bodies in Delhi. In Proceedings of the H04, IAHS-IAPSO-IASPEI Assembly, Gothenburg, Sweden, 22-26 July 2013; pp. 361-368.

52. Li, J.; Song, C.; Cao, L.; Zhu, F.; Meng, X.; Wu, J. Impacts of landscape structure on surface urban heat islands: A case study of Shanghai, China. Remote Sens. Environ. 2011, 115, 3249-3263.

53. Jiang, J.; Tian, G. Analysis of the impact of land use/land cover change on land surface temperature with remote sensing. Proc. Environ. Sci. 2010, 2, 571-575.

54. Deng, C.; Wu, C. Examining the impacts of urban biophysical compositions on surface urban heat island: A spectral unmixing and thermal mixing approach. Remote Sens. Environ. 2013, 131, 262-274.

(C) 2014 by the authors; licensee MDPI, Basel, Switzerland. This article is an open access article distributed under the terms and conditions of the Creative Commons Attribution license (http://creativecommons.org/licenses/by/3.0/). 